Taggart, M., Willis, C., and Hanahoe, J. (2019). Not Seeing the Wood for the Trees - a Gemba Walk through a Timber Framed Housing Development In: Proc. $27^{\text {th }}$ Annual Conference of the International. Group for Lean Construction (IGLC), Pasquire C. and Hamzeh F.R. (ed.), Dublin, Ireland, pp. 1209-1218. DOI: https://doi.org/10.24928/2019/0231

\title{
NOT SEEING THE WOOD FOR THE TREES - A GEMBA WALK THROUGH A TIMBER FRAMED HOUSING DEVELOPMENT
}

\author{
Martin Taggart ${ }^{1}$, Conor Willis ${ }^{2}$, and John Hanahoe ${ }^{3}$
}

\begin{abstract}
This applied research seeks to improve the efficiency of production planning on repetitive construction projects. Ireland currently has a pressing need for a rapid expansion of housebuilding and many projects are planned or underway. However, programming of such works has been poor historically. This research proposes approaches to make planning of such projects more efficient.

Information on a representative sample of dwellings was collected on a large timberframed housing site over a five-month period. The main-contractor's bar chart programme for the project was analysed using the Line of Balance production planning approach. This allowed the time waste inherent in the programme to be visualised and allowed options for improvement to be considered. The results showed that a significant improvement could be made in the programme and in the efficient use of resources. This has significant benefits for contractors. The research is based on a single case study, which constrains universal claims about the results reported. However, the authors note their extensive experience of visiting similar projects, allowing them to attest to the 'typicality' of the case study in the Irish SME marketplace. The work has implications for improving lean construction practice in production planning and suggests the need for additional training in technical education.
\end{abstract}

\section{KEYWORDS}

Gemba walk, Last Planner System, Line of Balance, Programming, Planning.

\section{INTRODUCTION}

This research is focused on improvement in production planning on construction projects of a repetitive nature. Ireland has a very pressing social need to rapidly expand housebuilding output towards meeting a significant current shortage and to address the additional needs of an expanding population (National Planning Framework, 2018). The National Planning Framework (2018), foresees the need of 550,000 new dwellings by 2040,

$1 \mathrm{PhD}$, Lecturer, Dept. of Building and Civil Engineering., Galway-Mayo Institute of Technology, Galway, Ireland, +35391 742875, martin.taggart@gmit.ie

2 Honours Student, Dept. of Building and Civil Engineering., Galway-Mayo Institute of Technology, Galway, Ireland +35385 2125736, conorwillis5@gmail.com

3 Senior Lecturer, Dept. of Building and Civil Engineering., Galway-Mayo Institute of Technology, Galway, Ireland, +353 87 2604262, john.hanahoe@ gmit.ie 
however, progress towards this target is very slow and inefficient. Irish house builders have traditionally used very simple Gantt charts as a means of programming time on their projects. Whilst they are familiar with this simple approach, it can be strongly argued that it is normally an inefficient means of programming as it provides little real-time information about what is happening on site (Seppänen et. al, 2014). Koskela (2014), suggests that such approaches, normally supported by critical path theory, have serious limitations when attempting to model the particular complexity of construction projects.

Motivation for this paper came from a Gemba walk around a housing development of 200 timber framed dwellings. The site manager professed himself happy that work was being carried out in an efficient and timely manner. However, it was immediately obvious that a large majority of the dwellings stood empty, at various stages of construction. Workers progressed only a small number of the units at any one time. The research herein, illustrates how the adoption of a Line of Balance approach could inform and improve the programme of works used on the site and also inform future projects.

\section{APPROACHES TO PRODUCTION PLANNING}

\section{Programming Literature}

Cooke and Williams (2013) detail the following common types of programming techniques which are used in construction: bar (or Gantt) charts; linked bar charts; arrow diagrams; precedence diagrams; line of balance; and time-chainage diagrams. The underlying theory associated with many of these techniques is that of the Critical Path Method (CPM). Most of the traditional methods of production control used in construction were developed in the manufacturing industries in the 1950s (Koskela et al., 2014). Koskela et al., (2014) and Kenley and Seppänen (2009) chart the pervasive dominance of CPM in the construction industry, whilst also providing a detailed critique of the many flaws associated with the CPM approach. A principal criticism by Koskela et al., (2014) is that CPM has morphed from being a potentially useful method of production control into a method of contract control. Clients have adopted it as a very useful mechanism for pinning blame for contractual delays. Seppänen et. al (2014) observes that CPM is the primary planning methodology used in construction but notes its inefficiency. When considering CPM in the lean construction paradigm, the principal intent of CPM is to optimise the technological linkages of activities. Biotto et al., (2017) categorise CPM as an activity-based planning tool. Such tools are widely criticised by lean construction researchers for their inability to deal with construction complexity, or provide a smooth, uninterrupted project work flow. Smooth work flow is both a central tenet of the lean construction philosophy and a highly desirable outcome for the sub-contractors, who physically execute most of the work on Irish construction sites.

As a response to the issues described above, the Last Planner System methodology was developed, originating from a lean philosophical approach by Ballard (1994). The Last Planner System is directly focused on construction work, whereas traditional tools have evolved from manufacturing. At its core, the Last Planner System seeks to maintain workflow in the construction process, avoiding the stop/start workflows traditionally associated with the industry. A central proposition of the Last Planner System is that the 
whole project team should be involved in planning and then executing the work. All other things being equal this should provide a better planning outcome, whilst avoiding the lack of ownership of production programmes seen on most construction projects (Johansen \& Porter, 2003).

The development of the Last Planner System approaches has engaged significant interest from the lean community, notably, several hundred papers have been submitted to past IGLC conferences on the subject. However, the Last Planner System still requires suitable input data from project stakeholders to achieve a smooth project workflow. A typical approach to this task is to help stakeholders 'visualise' the steps of the process they are planning to undertake.

From multiple field observations made by the authors, It is clear that in Ireland, the predominant form of project programming on SME construction projects is via the use of simple bar (or Gantt) charts. There is also some evidence that on a small number of projects, efforts have been made to apply critical path analysis techniques, such as CPM, to inform the efficiency of the bar chart's contents. However, this does not appear to be widely or systematically developed in our view. The use of the Last Planner System is very rare in Ireland with the authors only having encountered a handful of projects using this approach. Biotto et al. (2017) situate Line of Balance squarely within the Lean Construction paradigm, claiming it as a valid tool for Lean Construction enquiry. Kenley and Seppänen (2009) contend that construction can benefit from taking a fresh look at some of the methods that have been discarded in the race to adopt CPM as the one best approach.

\section{LINE OF BALANCE PLANNING}

Line of Balance (LOB) is a tool for project planning and control that provides great visibility for the flows of work in a construction site (Kemmer et al., 2008). It is an established variation of linear scheduling/linear programming and time/location methods (Moura, Monteiro \& Heineck, 2014). Biotto et al., (2017) note that LOB is a tool for production design, that expresses the work structure in a visual fashion. The work locations of the project are used as the unit basis for planning and control. The approach is used in the construction industry for projects that are typically of a repetitive nature. LOB diagrams visualise the planning, typically using suitable quantity units on the vertical axis and time on the horizontal axis (but can be reversed in some situations). The activity lines typically slope to the right, representing the planned rate of delivery of the units. The LOB approach is focused on improving continuity of work. A continuous flow is sought, trying to minimise trade group conflicts and ensuring interruptions are avoided. Continuous flow is created by ensuring work location spaces on site are used efficiently (Kankainen \& Seppänen, 2003).

Kankainen and Seppänen (2003), suggest the use of LOB as a viable option to check the feasibility of the project master plan (bar charts) before they are executed. Schramm, Costa, and Formoso (2004), found that LOB could be used to define and simulate the workflows and the pace of each work crew. The object being to identify the interfaces between production crews, and where necessary and possible, change their pace or sequences to avoid clashes. Changes in the production resources available may also be

needed to achieve this balance. Moura, Monteiro and Heineck (2014), state that LOB 
suggests all activities are to be performed with a single output rate, making it a parallel programme, with no wasted time between the end of one activity and the beginning of another, save for a contingency buffer. Where two or more activities occupy the same location space and are performed at the same time, a potential negative impact on productivity pertains. LOB helps visualize these potential conflicts and allow corrective actions if needed.

Lean construction researchers have noted the possibilities of LOB as an effective Lean tool (Kankainen \& Seppänen, 2003). The approach has not, however, attracted much interest within the IGLC research community, with LOB attracting less than one paper per year, on average, at IGLC conferences. Mendez and Heineck (1999), similarly suggest that LOB has not engaged the interest of practitioners. They speculated that a lack of suitable LOB software (as opposed to plentiful options for CPM) may explain the dominance of CPM. They note that CPM directly identifies a critical path, but also details non-critical activities, suggesting that, the latter must surely contain some potential element of wasted time. Kemmer et al., (2008) considered some of the case studies on LOB presented in the IGLC literature to be trivial in nature, concerned with theory, but not much with practice. The authors present results of their own case study where LOB was used as a visualisation tool, enabling site management and other stakeholders to investigate their plans in terms of: determination of appropriate batch size, number of work teams, number of members of work teams and cycle times. LOB diagrams were presented for various planning scenarios that the project team could discuss and refine. Kemmer et al., (2003) noted that the approach did indeed assist greater efficiency. However, they also noted cultural barriers mitigated against acceptance of Lean construction methods. For instance: the smoother work flow led to more pressure on supervisors to keep up. Additionally, workers were concerned at how bonus payments could be lost or reduced in the newly efficient plans. Similar examples of cultural resistance are noted elsewhere where Lean interventions into programming and planning spheres were implemented (Johansen \& Porter, 2003).

\section{GEMBA WALK}

Samudio, Alves and Chambers (2011) discuss the importance of 'going and seeing' to the construction process. They found that adopting this approach provided valuable insights into production cycle times; waiting time; inventory; and rework. They trace the antecedents of Gemba walks back to Ohno and Shingo in Lean manufacturing, who documented many instances where they had visited the workplace to obtain clear insights into problematic issues and associated practice. Gemba is the Japanese word for 'actual place' - This concept was developed in the Lean manufacturing paradigm into the practice of Gemba walks. Samudio, Alves and Chambers (2011) note the essential ingredient of involving the workforce and stakeholders in developing collaborative approaches and providing their expertise and insight into the planning effort. Koskela et al. (2014), in contrast note that the typically 'top down' approach of CPM programming and centralized planning does little to support site management in their endeavors. The authors, herein, can report that their experiences show that the typical approach of the Irish SME sector is to adopt a command led programming approach, with limited input into production planning from sub-contractors or other stakeholders. This is very much a top down agenda. 


\section{AN IRISH CASE STUDY}

\section{CASE STUDY RESEARCH METHODOLOGY}

A case study for one project in Ireland is presented below. Yin (2011) notes the use of exploratory case studies as a suitable method to extract both implicit and explicit data, from complex situations. In this case author two, worked on the case study project full time as part of an industrial work placement, working as assistant site manager. This allowed immersive access to contractor data as well as real time observation of what happened on site. Single cases give rise to questions of generalizability of the results, which is a limitation of this research. However, Flyvbjerg (2006) argues strongly for the possibility of recontextualising learning from case studies in other simpler contexts. Interestingly, Seppänen et al., (2014) recommend case study for investigating the complex variables involved in construction planning.

The case study project involved circa 200 dwellings, mostly semi-detached homes, constructed in phases. Some terraced houses, for social housing were also provided. The value of the project was circa 50 million euro. The construction techniques used on the site are typical in terms of the use of open panel, timber frame construction in Ireland. The production planning approach adopted by the main contractor for the project was the use of simple bar charts, without any critical path evaluation. The authors note that this approach is typical of planning approaches for SME construction companies in Ireland.

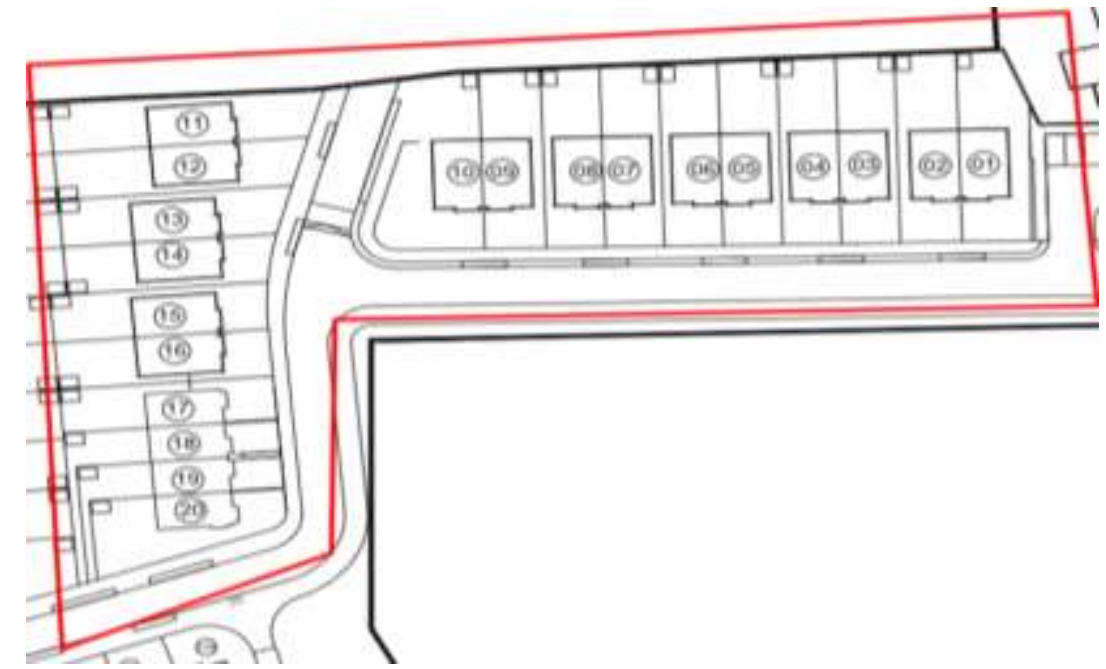

Figure 1: Partial site plan, showing sample of 20 dwellings on the case study project

The main contractor developed a simple bar chart programme for the works, which was distributed to sub-contractors as the principal means of time management on the project. The study focused on a representative sample of data from 16 semi-detached and 4 terraced homes on the site (Figure 1). The main-contractor's contractual bar chart programme was compared with observational data collected from the 20 homes. This involved keeping a daily log, over a five-month period, recording the progress made/work carried out on each of the 20 homes in tabulated form. This information was compared to what was originally planned to happen on the contractors Gannt chart. The contractor's base information was 
then modelled using LOB techniques, to produce a more efficient, less wasteful programme of works.

\section{Analysis of main Contractors Programme}

The network diagram (Figure 2) shows the sequence of the work. The work has been divided into four elements. Substructure, Timber frame erection, Superstructure and External works/finishes. These 4 elements are represented graphically throughout this section in both Gantt/bar chart and Line of Balance formats.

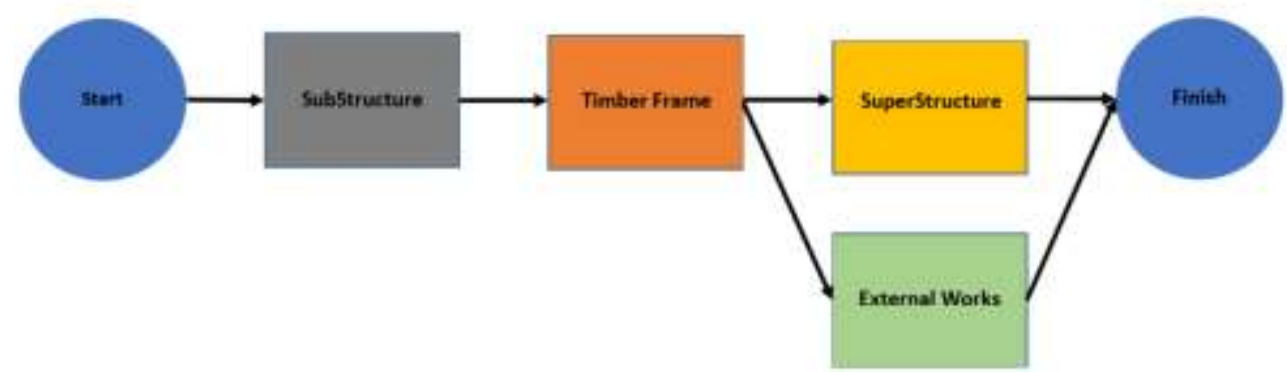

Figure 2: Sequence of activities

The primary format of scheduling used by the main contractor was a bar chart. Figure 3 , below, shows the main contractors original programme intention in a simplified bar chart layout. The intention was to complete the 20 sample dwellings in a period of 37 weeks.

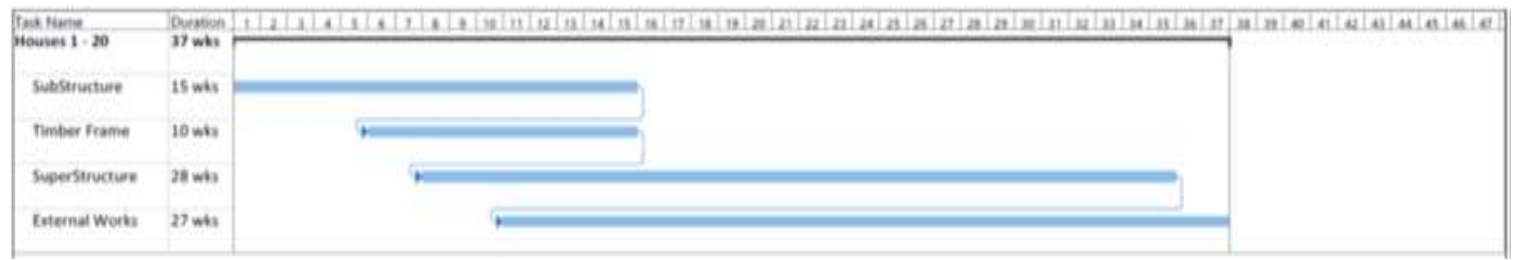

Figure 3: Original plan in simplified bar chart format

It was observed that the programme was not being used for reference by the subcontractors. It was also clear from an early stage that the project was behind its original schedule. Figure 4 shows the actual durations of the elements and that this part of the project actually took 47 weeks to complete. Unfortunately, Figure 4 is not of any great assistance in understanding why this delay occurred.

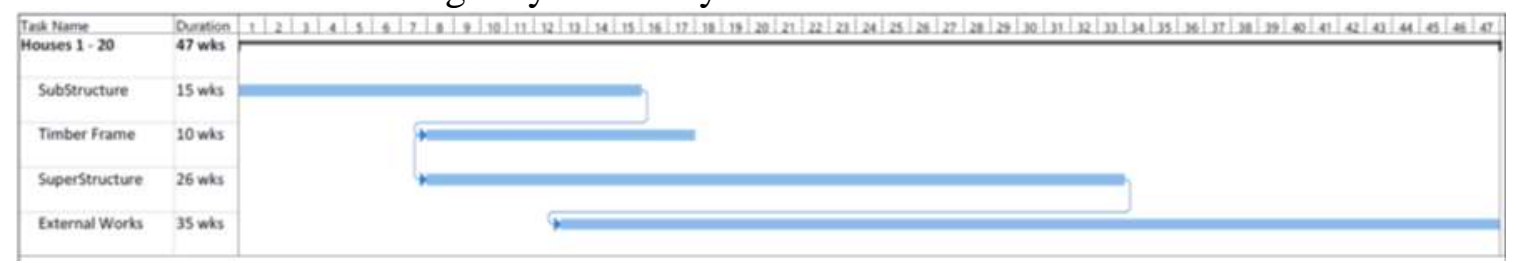

Figure 4: Actual durations observed in simplified bar chart format.

Table 1 shows the actual durations of each element for each house pair. This information, while useful, is still difficult to visualise. 
Table 1: Actual timings observed in tabular format

\begin{tabular}{ccccccccc}
\hline & \multicolumn{3}{c}{ Substructure } & \multicolumn{2}{c}{ Timber Frame } & \multicolumn{2}{c}{ Superstructure } & \multicolumn{2}{c}{$\begin{array}{c}\text { Services \& Ext. } \\
\text { Works }\end{array}$} \\
\hline House & Start & Finish & Start & Finish & Start & Finish & Start & Finish \\
$1 \& 2$ & 1 & 3 & 11 & 12 & 13 & 24 & 16 & 27 \\
$3 \& 4$ & 2 & 3 & 8 & 9 & 10 & 24 & 13 & 29 \\
$5 \& 6$ & 2 & 6 & 9 & 10 & 11 & 25 & 14 & 30 \\
$7 \& 8$ & 2 & 6 & 10 & 11 & 12 & 26 & 15 & 29 \\
$9 \& 10$ & 3 & 9 & 12 & 13 & 14 & 30 & 17 & 35 \\
$11 \& 12$ & 3 & 9 & 17 & 18 & 19 & 34 & 25 & 47 \\
$13 \& 14$ & 4 & 11 & 16 & 17 & 18 & 33 & 22 & 42 \\
$15 \& 16$ & 4 & 11 & 15 & 16 & 17 & 32 & 21 & 40 \\
$17-20$ & 4 & 15 & 13 & 14 & 15 & 36 & 18 & 37 \\
\hline
\end{tabular}

Figure 5 shows the same information in a Line of Balance format.

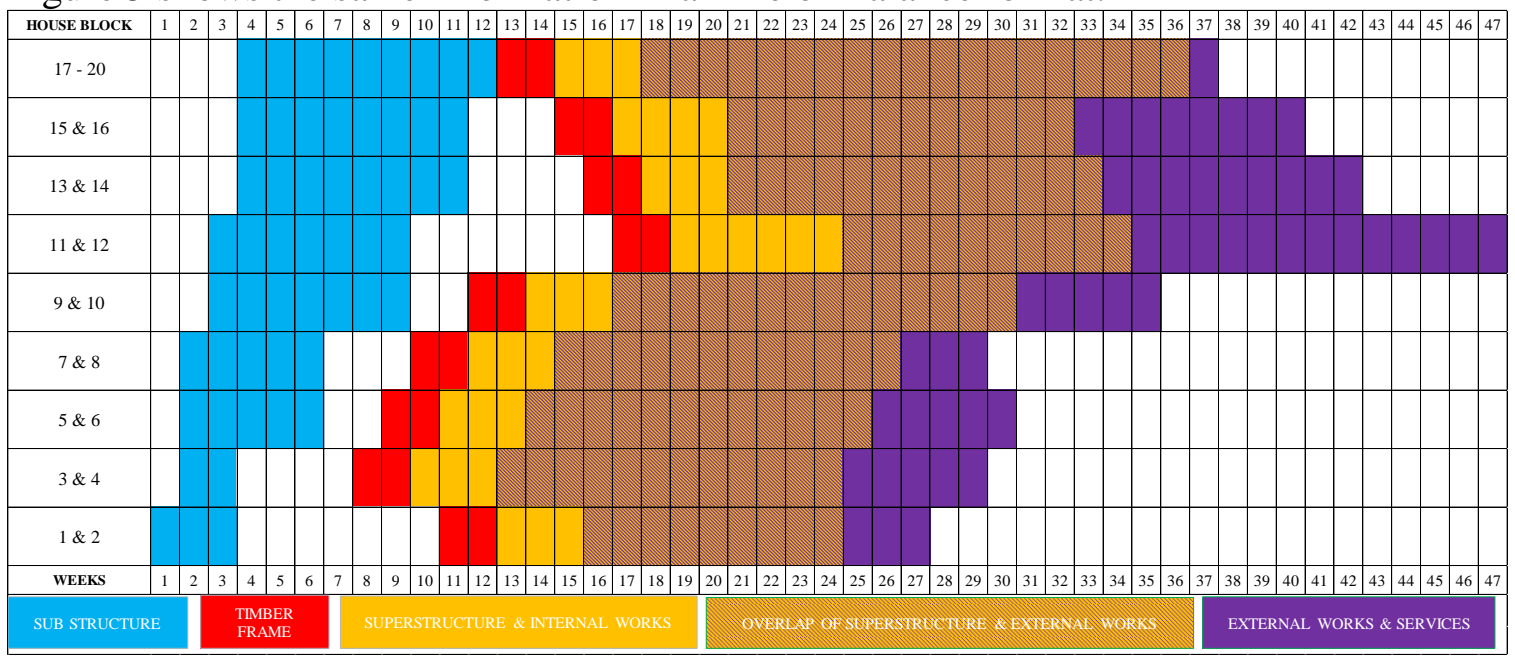

Figure 5: Actual sequence of work in Line of Balance format

When the same information is presented in this format, it gives a much better insight into the work sequence.

- The original (planned) duration was 37 weeks, but the actual duration was 47 weeks

- The substructure elements took 2 weeks for some units and up to 8 weeks for others.

- There is no logical or efficient sequence to the elements

- The timber frame element happened in a different sequence to the substructure. The timber frame element was sequenced based on the supplier's schedule rather that the onsite requirements.

Figure 6 shows a proposed improved sequence. This allows for much better continuity of work, with crews moving from unit to unit in a clear logical way. It also allows for a 
Taggart, M., Willis, C., and Hanahoe, J.

contingency buffer between activities. Further improvements become more evident which would benefit the programme (including speeding up the rate of timber frame erection) should resources allow.

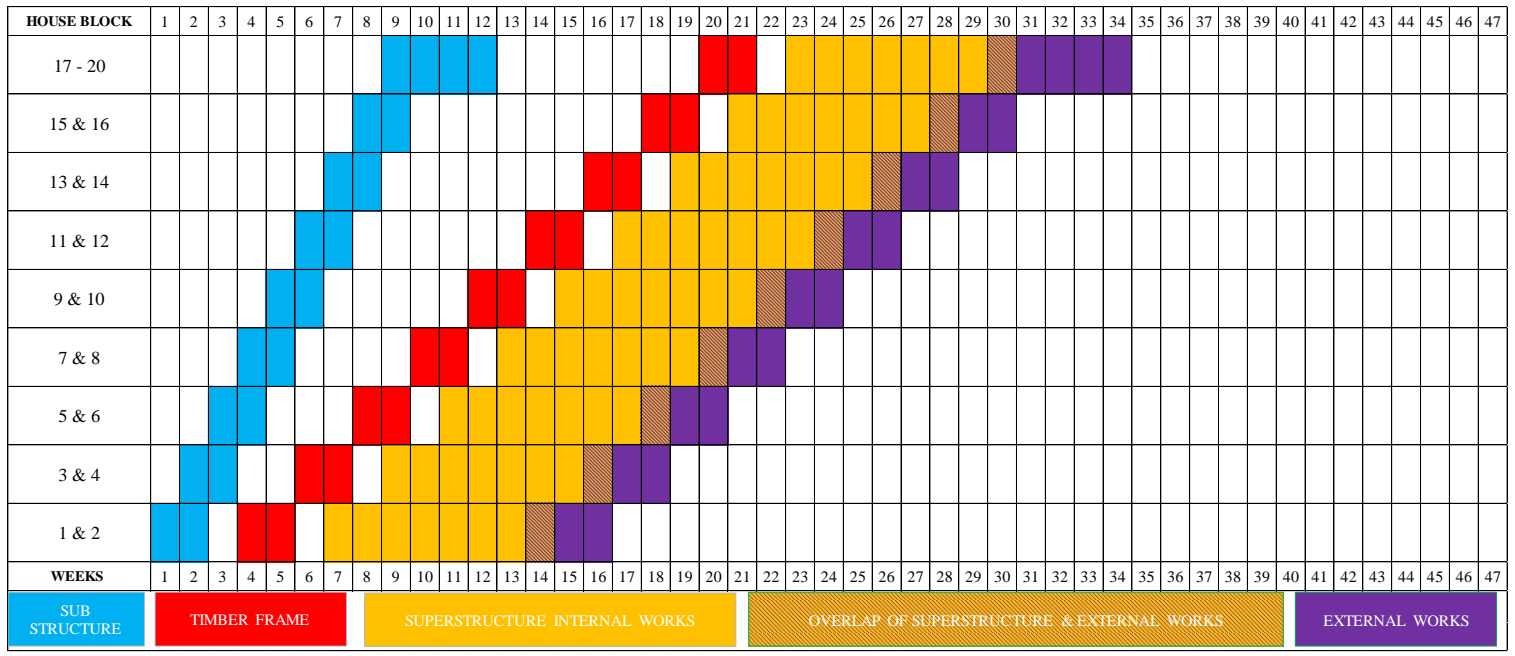

Figure 6: Proposed sequence of work in Line of Balance format

Table 2: Proposed timings in tabular format

\begin{tabular}{ccccccccc}
\hline & \multicolumn{2}{c}{ Substructure } & \multicolumn{2}{c}{ Timber Frame } & \multicolumn{2}{c}{ Superstructure } & \multicolumn{2}{c}{ Services \& Ext Works } \\
House & Start & Finish & Start & Finish & Start & Finish & Start & Finish \\
\hline $1 \& 2$ & 1 & 2 & 4 & 5 & 7 & 14 & 14 & 16 \\
$3 \& 4$ & 2 & 3 & 6 & 7 & 9 & 16 & 16 & 18 \\
$5 \& 6$ & 3 & 4 & 8 & 9 & 11 & 18 & 18 & 20 \\
$7 \& 8$ & 4 & 5 & 10 & 11 & 13 & 20 & 20 & 22 \\
$9 \& 10$ & 5 & 6 & 12 & 13 & 15 & 22 & 22 & 24 \\
$11 \& 12$ & 6 & 7 & 14 & 15 & 17 & 24 & 24 & 26 \\
$13 \& 14$ & 7 & 8 & 16 & 17 & 19 & 26 & 26 & 28 \\
$15 \& 16$ & 8 & 9 & 18 & 19 & 21 & 28 & 28 & 30 \\
$17-20$ & 9 & 12 & 20 & 21 & 23 & 30 & 30 & 34 \\
\hline
\end{tabular}

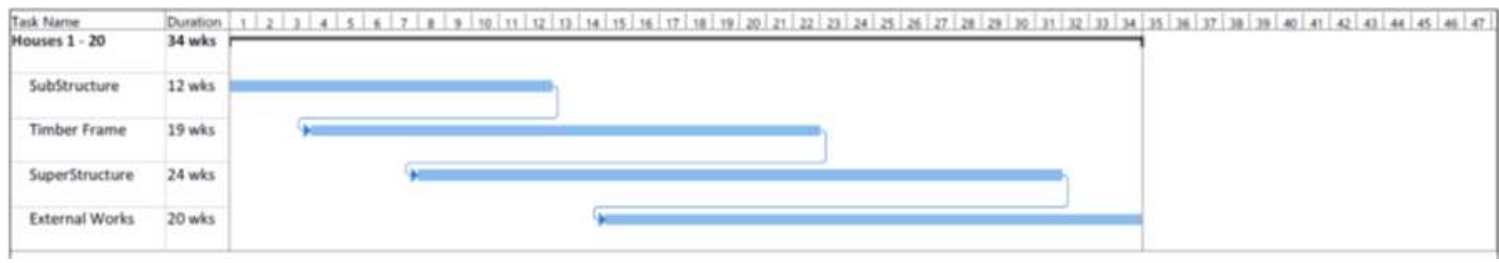

Figure 7: Proposed schedule presented in simplified bar chart format

Table 3: Time savings in tabular format

\begin{tabular}{cccccc}
\hline Ref & Substructure & Timber Frame & Superstructure & Services \& Ext Works \\
House & Actual Proposed & Actual Proposed & Actual Proposed & Actual & Proposed \\
\hline
\end{tabular}




\begin{tabular}{lllllllll}
\hline $1-20$ & 15 & 10 & 10 & 18 & 36 & 30 & 47 & 34 \\
\hline
\end{tabular}

There is a potential saving in time of 13 weeks compared to the observed duration time of 47 weeks. There is a 16-week period allocated to the construction of each block of the sample (consisting of two semi-detached units or 4 terraced houses). Within these 16 weeks, there is some buffer time provided. Buffer time allows for adjustments if unforeseen circumstances are encountered.

This illustrates that the use of the Line of Balance can enhance the programming of repetitive work, such as timber frame housing. The proposals made do not deviate from the original sequence, as shown in Figure 2. The proposals simply order the project into a more efficient programme. The aim of the proposal is to demonstrate the potential of Line of Balance to assist in creating better work flow in repetitive projects.

\section{CONCLUSIONS}

The case study has established that significant time savings can be achieved by the application of LOB techniques to this repetitive housing project. Problems with the existing work flow sequencing in the main contractor's bar chart programme were more easilyvisualised using LOB in the case study, suggesting that if a more efficient plan (focussing on maintaining flow) was adopted, that the sample of 20 houses could have been completed 13 weeks earlier. The importance of collecting accurate and detailed base data from the site, to improve planning efforts over time, was also established. The potential for wider generalisation was also considered. Whilst this paper reports from a single case study, the authors note, from their field experience, the typicality of the approach used by the SME main contractors to production planning in Ireland. This suggests significant potential for contractor practitioners to improve their production planning, utilising the LOB approach. The work also highlights the potential for LOB to provide accurate project data for use in lean programming approaches, such as the Last Planner System. The implementation of production planning improvements can encounter resistance for a variety of reasons. Such resistance should be expected and diffused by engaging the stakeholders in the planning process. This research presented the results of a hypothetical analysis into the potential for improvement. The authors are currently working with the main contractor, towards application of LOB to improve their programming on forthcoming projects. This will give greater insights into the potential for LOB in production planning.

\section{REFERENCES}

Ballard, G. (1994). The last planner. Northern California Construction Institute, Monterey, California, 1-8.

Biotto, C. , Kagioglou, M. , Koskela, L. \& Tzortzopoulos, P. 2017, 'Comparing Production Design Activities and Location-Based Planning Tools ' In:, 25th Annual Conference of the International Group for Lean Construction. Heraklion, Greece, 9-12 Jul 2017. pp 705-712 
Cooke, B., \& Williams, P. (2013). Construction planning, programming and control. John Wiley \& Sons, Oxford.

Flyvbjerg, B. (2006). Five misunderstandings about case-study research. Qualitative inquiry, 12(2), 219-245.

Johansen, E., \& Porter, G. (2003). An experience of introducing last planner into a UK construction project. In:, 11th Annual Conference of the International Group for Lean Construction. Virginia, USA, 1.

Kankainen, J. \& Seppänen, O. (2003), 'A Line-of-Balance Based Schedule Planning and Control System' In:, 11th Annual Conference of the International Group for Lean Construction. Virginia, USA, 1-. pp 132-143

Kemmer, S.L. , Heineck, L.F.M. \& Alves, T.D.C. (2008), 'Using the Line of Balance for Production System Design' In:, Tzortzopoulos, P. \& Kagioglou, M., 16th Annual Conference of the International Group for Lean Construction. Manchester, UK, 16-18 Jul 2008. pp 299-308

Kenley, R., \& Seppänen, O. (2009, December). Location-based management of construction projects: Part of a new typology for project scheduling methodologies. In Winter Simulation Conference (pp. 2563-2570). Winter Simulation Conference.

Koskela, L., Howell, G., Pikas, E., \& Dave, B. (2014). If CPM is so bad, why have we been using it so long?. 22nd Annual Conference of the International Group for Lean Construction. Oslo, Norway, 25-27 Jun 2014

Mendez Jr., R. \& Heineck, L.F.M. (1999), 'Towards Production Control on Multi-Story Building Construction Sites' In:, 7th Annual Conference of the International Group for Lean Construction. Berkeley, USA, 26-28 Jul 1999. pp 313-324

Moura, R.D.S.L.M. , Monteiro, J.M.F. \& Heineck, L.F.M. (2014), 'Line of Balance - Is It a Synthesis of Lean Production Principles as Applied to Site Programming of Works?

' In:, Kalsaas, B.T., Koskela, L. \& Saurin, T.A., 22nd Annual Conference of the International Group for Lean Construction. Oslo, Norway, 25-27 Jun 2014. pp 703714

National Planning Framework (2018), Department of Housing, Planning and Local Government. http://npf.ie/wp-content/uploads/Project-Ireland-2040-NPF.pdf Accessed: $11^{\text {th }}$ April 2019.

Seppänen, O., Evinger, J., \& Mouflard, C. (2014). Effects of the location-based management system on production rates and productivity. Construction management and economics, 32(6), 608-624.

Samudio, M., da CL Alves, T., \& Chambers, D. (2011). Employing the principle of" going and seeing" to construction. Lean Construction Journal.

Schramm, F.K. , Costa, D.B. \& Formoso, C.T. 2004, 'The Design of Production Systems for Low-Income Housing Projects' In:, Bertelsen, S. \& Formoso, C.T., 12th Annual Conference of the International Group for Lean Construction. Helsingør, Denmark, 35 Aug 2004

Yin, R. K. (2011). Applications of case study research. sage. 